\title{
SOCIABILIDADE E FRAGMENTAÇÃO SUBJETIVA: REFLEXÕES SOBRE A CONSTITUIÇÃO DO INDIVÍDUO MODERNO A PARTIR DE GEORG SIMMEL
}

\author{
Wallace Faustino da Rocha Rodrigues ${ }^{l}$
}

\begin{abstract}
RESUMO
0 objetivo do texto é articular as concepções de Simmel sobre a subjetividade humana, observadas em estudos referentes à cultura, com a forma de sociabilidade estabelecida. 0 foco volta-se, portanto, para a maneira como o social é estruturado por meio da articulação da subjetividade com as interferências da objetividade na formação do indivíduo moderno. Por fim, tenta-se apresentar questionamentos provenientes desta opressão objetiva e a consequente fragmentação da subjetividade.
\end{abstract}

Palavras-chave: Simmel. Sociabilidade. Subjetividade. Modernidade.

\footnotetext{
${ }^{1}$ Doutorando do Programa de Pós-Graduação em Ciências Sociais da Universidade Federal de Juiz de Fora, Brasil.wallacefaustinorocha@hotmail.com.

Agradeço os valiosos comentários da professora Rogéria Dutra e de Robson Rocha, assim como a paciência na discussão de alguns dos pontos aqui abordados. Entretanto, como de praxe, eximo-os de toda e qualquer responsabilidade quanto ao presente artigo.
} 


\section{SOCIABILITY AND SUBJECTIVE FRAGMENTATION: REFLECTIONS ON THE CONSTITUTION OF THE MODERN INDIVIDUAL THROUGH GEORG SIMMEL'S STUDIES ABSTRACT}

This paper purports to relate Simmel's conceptions on human subjectivity, observed in culture related studies, with the established form of sociability. I focus on how the social is structured in terms of the articulation of subjectivity with the interferences of objectivity in the formation of the modern individual. Finally, the paper attempts to present interrogations pertaining to such objective oppression and the consequent fragmentation of subjectivity.

Keywords: Simmel; sociability; subjectivity, modernity.

partir da indubitável importância do pensamento de Simmel para as Ciências
Sociais, tal como a sua interpretação singular da modernidade (demarcada pela
grande importância do indivíduo na construção de um universo cultural notoriamente digno de consideração) tenta-se, num primeiro momento, apresentar algumas das principais características de sua reflexão acerca da constituição do todo social, tomando como referência os termos subjetividade e objetividade. Para tanto, ressaltam-se alguns dos aspectos centrais de sua sociologia, tal como a sua possibilidade de compreensão deste todo, sempre pautado pela relevância do elemento histórico e das ações dos sujeitos - embora neste último caso possa-se falar em um determinismo restrito pela importância dos objetos para a criação desta realidade.

Em seguida, atenta-se para a singularidade da modernidade neste processo dialético (subjetividade-objetividade), demarcado pelo princípio concreto-abstrato. Ressalta-se 0 aspecto fragmentário imposto por esta mesma modernidade na caracterização do universo social. Logo, pressupõe-se que a partir desta concepção de Simmel, a configuração do indivíduo será de uma subjetividade distinta, particular, caracterizada pela sua fragmentação, fruto dos limites impostos pela forma produtiva moderna em que a produção adquire um status superior aos próprios objetos produzidos. Nas considerações finais, portanto, enfatiza-se que o mundo moderno se caracteriza exatamente pela irrupção da suposta fragilidade subjetiva advinda deste processo a limitar a capacidade de significação dos objetos, tal como a "colonização subjetiva" destes mesmos objetos.

A importância de se refletir sobre a formação da modernidade a partir de Simmel se encontra, justamente, na capacidade desse autor de sistematizar uma forma sociológica autêntica de se perceber o todo, incluindo um movimento dialético tanto 
quanto o sujeito e o universo material em que este se encontra. 0 produto final de sua sociologia é uma delimitação precisa das formas sociais, levando sempre em conta 0 universo em que o todo social se constitui, acentuando o sentido que um grupo social atribui a este todo. A compreensão da realidade, portanto, não estaria limitada à observação de um conjunto de ações individuais ou coletivas, mas, pelo contrário, à (re)significação constante que os indivíduos são capazes de processar. Mais atual que isso, impossível. Compreender um movimento de reflexão sociológica neste sentido permite uma abertura compreensiva do pesquisador, quanto as observações de fenômenos sociais não as assimilando somente como processos isolados, mas, como um constante fluxo dialético entre os indivíduos de uma comunidade e o todo em que se encontram inseridos.

\section{INDIVÍDUO E SOCIEDADE: UM TODO}

Enquanto pensador do princípio do século XX, inevitavelmente, Simmel se depara com as conseqüências da modernidade no desenvolvimento social e, fundamentalmente, com as formas de organização das sociedades. É possível até afirmar que foram justamente essas consequências da modernidade que motivaram sua atividade intelectual. A sua percepção do moderno - e tudo dela advindo - é feita ao atentar para a particularidade da constituição social humana, tentando compreender a constante atribuição de sentido dada às coisas ao seu redor. Aliás, este sentido torna-se fato condicional para a maneira como o autor aprisionará alguns dos elementos mais característicos de seu universo social. Logo, é assim que Simmel procura compreender 0 indivíduo, tal como suas atitudes racionais, promovendo um fatal distanciamento de uma perspectiva puramente teleológica, o que obriga a assimilar o mundo como um produto das atividades humanas.

Deste modo, Simmel caminha para o reconhecimento do indivíduo em sociedade, seja questionando a tradição iluminista e a sua visão naturalizada do homem, seja em uma perspectiva também crítica quanto ao kantismo e ao indivíduo definido como algo puramente racional (WAIZBORT, 2006). Em sua definição, o fundamental é o entendimento quanto à forma assumida pela individualidade não como fruto da ação, mas como construção de movimentos internos e externos, do homem em relação ao seu meio e da maneira como o meio dialoga com a constituição humana. A individualidade, portanto, abrange o indivíduo em seu mundo, tal como a maneira como ele percebe este mundo em um movimento ad infinitum de construção de si mesmo para, então, falar-se em uma construção do universo em que se encontra inserido. Assim, torna-se impossível falar do indivíduo como algo distante de seu meio social. 
Quando o homem é realmente ele próprio, possui uma força concentrada suficiente não apenas para a própria autopreservação, mas, por assim dizer, transborda para outros, permitindo a recepção desses outros em si mesmo e a identificação com estes. Somos tanto mais valoráveis eticamente tanto mais bondosos e capazes de compaixão quanto mais cada um é si próprio, ou seja, quanto mais cada qual permite que aquele núcleo interno se torne autônomo e soberano, admitindo, assim, a identificação entre os homens para além da confusão das ligações sociais e papéis fortuitos (SIMMEL, 1950 apud WOLF, 1950, tradução livre do autor).

Notavelmente, diante desse quadro, considerar sociologicamente as relações sociais é admitir a imersão do sujeito neste todo em que faz parte. Manifestar a individualidade, então, é manifestar toda uma característica social à qual o sujeito se encontra inevitavelmente atrelado. Não se trata de ausência de autonomia, mas, pelo contrário, de identificar a autonomia como algo mais amplo, abranger a capacidade de $o$ indivíduo processar um conjunto de informações provenientes do universo social ao que pertence, dando sentido à sua própria existência. Somente a partir desta existência cujo sentido está condicionado à sempre potencial relação de troca com o todo - é que se pode falar em autonomia para a ação. Trata-se de perceber que a ação somente faz sentido por ela ser social.

De certa forma, é deste ponto que Simmel apreende a interlocução constante do indivíduo com o meio, particularmente evidente em sua preocupação em elaborar uma sociologia geral, outra, formal e, por último, uma sociologia filosófica. 0 resultado disso é a valorização do elemento histórico (no caso da sociologia geral), a sua superação a partir da cuidadosa observação entre as formas de associação que fazem a sociedade, estruturando as inevitáveis interações entre os indivíduos (eis a sociologia formal) e, finalmente, a admissão do questionamento filosófico no interior da sociologia como um todo (VANDENBERGHE, 2006).

Diante deste quadro, a reflexão proposta por Simmel acerca da essência da individualidade, assim como a liberdade para a sua manifestação, permite a ênfase na totalidade da vida histórica de uma sociedade - bem como suas variações históricas - e a inevitável interação social entre os indivíduos, sustentando-se em princípios livremente caracterizados como microssociológicos, ao abrir caminhos para a compreensão acerca daquilo que faz sentido para uma sociedade e, portanto, para que os indivíduos interajam entre si (VANDENBERGHE, 2006).

Neste caso, o que se encontra em evidência é a necessária consideração quanto à heterogeneidade do social, uma heterogeneidade demarcada tanto por um processo histórico de constituição social, quanto nos termos em que se dará a relação social propriamente dita. Para uma análise sociológica, a base subjetiva da constituição do 
sujeito e a participação desta subjetividade na consolidação dos processos sociais tornam-se proeminentes. Diante deste enquadramento, faz-se premente refletir sobre 0 formato da sociedade a partir da modernidade. A configuração do sujeito social, mediante as singulares características modernas, torna-se alvo de investigação de maneira que se possa compreender com precisão a modernidade por meio de seu sentido, o que destacaria uma fragmentação da subjetividade.

\section{ENTRE O OBJETIVO E O SUBJETIVO}

Mediante as reflexões aqui promovidas, nota-se como a objetividade em Simmel não pode ser vista como algo puramente instrumental (passivamente manipulado pela razão), mas como a manifestação de elementos externos à constituição humana, considerados fundamentais para as interações sociais, principalmente quando se toma como referência o fato de que a subjetividade aprisiona os elementos objetivos num processo constante e ininterrupto de construção do sujeito. Assim sendo, as interações sociais estariam condicionadas a este processo de permanente construção das subjetividades e à maneira como os sujeitos se relacionariam com o elemento objetivo da vida social.

Nesse sentido, o pensamento de Simmel é absolutamente diferenciado daquele visualizado por Weber em sua concepção de indivíduo moderno, como aquele em que aprisionariam os objetos como meio para a consecução de seus objetivos (WEBER, 2005). A negação weberiana do elemento filosófico na constituição de uma sociologia em Simmel, no entendimento de Vandenberghe (2006), impede que se compreenda 0 elemento objetivo, a objetividade, como algo capaz de construir constantemente a subjetividade e, portanto, o indivíduo em um processo social.

Por isso Simmel (2006a) fala em uma preponderância do objeto sobre o sujeito. Há, notavelmente, um princípio de constituição do sujeito a partir do objeto, qual seja, da forma como o sujeito assimila os objetos em uma vida em sociedade. Em um processo de construção de objetos - assim como do consequente relacionamento com eles - o sujeito colocaria neles "um pouco" de sua subjetividade que, de alguma forma, acaba contribuindo para o formato final deste objeto, inclusive determinando a maneira este como deve ser utilizado no interior da sociedade. Além disso, o seu uso contínuo no interior da sociedade, nas relações sociais, determina um conjunto de elementos outros que dizem respeito diretamente à característica fundamental do objeto, deixando de ser puramente algo material. Desta forma, há, novamente, uma assimilação subjetiva, constituindo um novo sujeito a partir da forma e da importância do lugar ocupado por este objeto no interior da sociedade. 0 indivíduo, nesta visão simmeliana, admite, portanto, uma nova constituição em termos de sua subjetividade (WOLF, 1950). 
Sem dúvida, Simmel manifesta-se a favor de como a objetividade se mostra determinante na constituição do sujeito, do indivíduo, tendo reflexos imediatos na forma como as interações sociais passam a ser estabelecidas. 0 resultado final disso é notável em termos de configuração de uma cultura e da forma como a cultura será assimilada e constituirá todo um modo de ser. Portanto, pensar uma fragmentação do sujeito a partir de uma perspectiva simmeliana, tomando como referência o elemento moderno e a constituição fragmentada do sujeito a ela embotada, acaba sendo uma discussão absolutamente profícua para a compreensão de um processo final de interação social e, por conseguinte, na maneira como se deve compreender uma determinada sociedade e, por sua vez, o sistema cultural em que ela se encontra.

A vantagem da análise sociológica de Simmel é a possibilidade conferida por ele de se ressaltar a perspectiva filosófica e, por conseguinte, um plano metafísico como referência para a compreensão de um todo social - aliás, esse é justamente o movimento proporcionado pela sua "terceira sociologia", conforme afirma Vandenberghe (2006). Tal metafísica se torna possível de ser percebida a partir do momento em que é caracterizado o papel ocupado pela subjetividade na definição do indivíduo, tal como o processo de determinação da cultura. Trata-se de uma cultura desenhada pela metafísica, perceptível ao se compreender a maneira como serão assimilados os elementos subjetivo e objetivo.

A síntese entre sujeito e objeto é exatamente o que permite a sua prescrição, uma vez que o resultado desta síntese está posicionado de forma definitiva na caracterização da cultura. Enfim, este fato contribui para um ganho epistemológico. 0 pensamento de Simmel transcende o aspecto puramente sociológico ao possibilitar o posicionamento do conhecimento em uma esfera filosófica. Logo, é visível uma relação mais complexa entre o objetivo e o subjetivo não a limitando a um plano instrumental e permitindo a compreensão do social como uma interação entre essas duas esferas, o que abre espaço para uma valorização da perspectiva cultural. Por isso, em Simmel, não há espaço para a consideração instrumental dos movimentos da sociedade, devendo a razão ser inserida neste movimento dialético que compreende tanto o plano objetivo quanto o subjetivo (WAIZBORT, 2006).

\section{A ANÁLISE SOCIAL DA MODERNIDADE}

A partir dos pressupostos trabalhados acima, a interpretação sociológica e a análise social da modernidade ganham corpo na obra simmeliana (SIMMEL, 2006a, WOLF, 1950). Vandenberghe posiciona o elemento social como algo a circunscrever toda e qualquer análise de seus inúmeros textos, tendo sempre como norte o mundo como um elemento, sobretudo social, e a realidade como parte deste mundo (VANDENBERGHE, 2006). 
Assim sendo, o reconhecimento do desenvolvimento da realidade em uma determinada história se torna algo necessário. Tal fato atenta para a existência de uma escassez da história, enquanto perspectiva filosófica, em seu propósito epistemológico de construção evolutiva do mundo com um processo constante de desenvolvimento dos seres humanos que nele habitam. Notavelmente, enquanto fator explicativo, a inevitabilidade da modernidade em seu aspecto essencialmente objetivo e de participação igualmente objetiva do indivíduo acentua o processo. Não obstante, para se chegar a tal proposta teórica, Simmel apresenta a sua definição de indivíduo em relação à sociedade e, igualmente, o importante lugar deste indivíduo para a constituição desta. De forma análoga, como já dito anteriormente, a sociedade influi de maneira definitiva na constituição do indivíduo (SIMMEL, 1971).

É com a consciência destes fatos que Simmel elabora um construtivo cruzamento entre o abstrato e o concreto na formação do indivíduo e, consequentemente, da sociabilidade. Isso retrata a importância de se considerar os elementos objetivos, demarcados essencialmente pelo aspecto concreto, que exige a apreensão elementar do abstrato. A compreensão deste pressuposto está condicionada à capacidade de percepção de subjetividades como aptas à construção do universo social em que os indivíduos se encontram. Assim sendo, torna-se premente conceber os diversos objetos a compor o todo social como dotados de elementos subjetivos responsáveis por sua caracterização. Ou seja, o entendimento da função ou espaço ocupado por determinado objeto somente é possível por meio da percepção que ele detém, um elemento subjetivo responsável por determiná-lo. Por conseguinte, as interpretações de Simmel incorrem na tentativa de compreensão do universo cultural em que os indivíduos se encontram inseridos, não concebendo os objetos materiais pura e simplesmente como instrumentos a serem utilizados, mas como portadores de caracteres subjetivos suficientemente consistentes. Com isso, Simmel vislumbra a composição de uma lógica socialmente compartilhada a partir de um movimento dialético entre o universo objetivo e o universo subjetivo, constituindo o que se chamaria de dialética do concreto (WAIZBORT, 2006).

Nossa ação, mesmo a totalidade de nosso ser, incluindo tanto o bonito como o feio, o certo como o errado, o grande como o pequeno, parece provir de um acervo de possibilidades, de modo que elas se relacionam com seu conceito, que expressa a sua lei interior e a sua essência lógica, sem que a significação deste conteúdo dependa do se, como e quão frequentemente ocorre sua realização (SIMMEL, 2005 apud SOUZA; ÖELZE, 2005, p. 48).

No fragmento acima, os termos conceito, lei interior e essência lógica reforçam a ideia da dialética do concreto na constituição do todo social. 0 autor pressupõe a existência de algo imanente à formação de cada objeto, que transcende o seu aspecto puramente material. Em seus argumentos está presente a noção de que esses objetos têm 
uma essência, o que proporciona uma possibilidade de análise ontológica deles, e, claro, da sociedade. 0 sentido, a existência, de tais objetos e o significado de sua matéria desde a forma como eles serão entendidos à maneira como serão assimilados e manipulados - depende da constituição do indivíduo imerso em uma sociabilidade. 0 indivíduo moderno está constantemente em processo social e, obviamente, compartilhando significados. A lógica para o entendimento da cultura segue justamente esta mesma linha reflexiva. É importante notar, ainda, que este movimento reflexivo de Simmel permite conferir ao indivíduo um protagonismo em suas ações, mas, igualmente, admite a existência de um relevante papel também para os demais elementos que, em outras condições, seriam considerados como secundários (isto é, apenas dignos de serem apropriados pelos seres humanos em questão).

Enfim, é pela singular maneira como Simmel apreende a noção de indivíduo e a consequente forma a considerar a integração deste indivíduo com o todo em que se encontra, em um movimento dialético, que se torna importante, senão fundamental, assimilar a maneira como este indivíduo admitirá a construção de sua realidade. 0 todo, portanto, não se torna um produto de suas ações, mas fruto dos movimentos de subjetividade e objetividade - as ações devem ser vistas neste meio. Obviamente, a maneira como tanto a subjetividade quanto a objetividade se configuram na modernidade capitalista se tornam essenciais para o entendimento das formas sociais contemporâneas.

\section{A FRAGMENTAÇÃO SUBJETIVA}

Diante da perspectiva teórica de Simmel, o real seria algo mais abrangente, que comporta tanto o elemento abstrato da constituição subjetiva dos indivíduos, quanto 0 concreto dos objetos materiais em si. Por conseguinte, sua compreensão se torna possível ao se tomar como referência o pressuposto de que o homem é composto pela sua subjetividade e objetividade - pela alma (como essência e, logo, manifestação pura de seus elementos mais subjetivos) e pelo espírito (que, na verdade, revela a parte consciente da alma), mantendo o sujeito em relação constante com o mundo.

0 espírito é o conteúdo objetivo daquilo que resulta consciente como função viva dentro da alma; alma é a forma que toma o espírito, isto é, conteúdo lógico conceitual do pensamento para nossa subjetividade, como subjetividade nossa. Neste sentido, pois, o espírito não está vinculado à configuração da unidade, sem a qual não existe alma. É algo assim como se os conteúdos espirituais pré-existissem dispersos de algum modo e, unicamente, a alma vem a compô-los conjuntamente, como matéria inanimada sendo incorporada ao organismo e à unidade da vida (SIMMEL, 2006b, p. 407, tradução livre do autor). 
Diante de tudo o que foi apontado, é possível a criação de um quadro reflexivo que leve em conta alguns dos principais aspectos abordados até 0 momento pela sociologia simmeliana. 0 horizonte de análise, notavelmente, é a consideração plena dos elementos subjetivos e objetivos para a composição dos aspectos gerais da realidade, de modo a conferir tanto o protagonismo do indivíduo na estruturação de seu universo, quanto a evidente relevância da objetividade enquanto detentora dos aspectos mais claros desta subjetividade e sua importância na construção de uma base cultural. Assim, dois pontos podem ser extraídos da afirmação de Simmel acerca da impossibilidade de apreensão completa do mundo ${ }^{2}$. Em primeiro lugar, o caráter essencialmente subjetivo do indivíduo não o permite assimilar de maneira completa a objetividade do mundo, juntamente com as significações. No entanto, observa-se a atribuição, ad infinitum, de novos sentidos provenientes da essência subjetiva dos indivíduos, fato que preconiza o ser humano como potencial construtor da realidade, com ações que, de alguma maneira, podem definir os rumos desta. 0 outro aspecto a ser destacado se refere à premissa de que o protagonismo dos inúmeros indivíduos que compõem uma sociedade confere uma multiplicidade de significações. Essa premissa é fundamental para reforçar a ideia da inesgotabilidade 3 do mundo. Como consequência, para se sentir satisfeito em um mundo de possibilidades inesgotáveis e compreensão completa comprometida, faz-se necessário que a capacidade de atribuição de sentido dos indivíduos esteja suficientemente desenvolvida. Não basta somente olhar a ação.

Ainda quanto a este último ponto, pode-se assumi-lo em uma perspectiva de inevitabilidade. Isto é, o mundo caminha para a modernidade e isso é algo inquestionável. Contudo, a modernidade, grosso modo, é caracterizada pela prerrogativa dos elementos objetivos definindo a realidade em que o indivíduo se encontra imerso. Parte-se do princípio da existência supostamente autônoma dos objetos na constituição do mundo, para afirmar que em termos de sociabilidade, o indivíduo (mesmo dotado de uma alma essencialmente subjetiva) tende a ser detentor de uma capacidade de

\footnotetext{
${ }^{2}$ Como se pode perceber ao longo do artigo, a apreensão incompleta do mundo não deve ser tomada como algo negativo. Pelo contrário, o caráter de incompletude dá-se essencialmente pela constante troca subjetividade-objetividade classificada em Simmel como dialética do concreto (WAIZBORT, 2006). Ou seja, o universo social é composto por elementos dos indivíduos da sociedade, não sendo mera conseqüência de suas ações. Contudo, em contrapartida, torna-se quase impossível um indivíduo assimilar de maneira plena, sem quaisquer alterações, aquilo que um determinado objeto pode representar para uma sociedade, isso, pelo menos, enquanto este indivíduo for possuidor de uma subjetividade capaz de agir de forma ativa na caracterização, na significação, deste objeto.

${ }^{3}$ Deduz-se a favor dessa compreensão do mundo, do real, como algo infinito justamente pela inesgotável capacidade de sentido que pode ser atribuído pelo indivíduo que apreende este mundo. A partir disso, afirma-se que apreender este mundo é obrigatoriamente atribuir sentido a ele e este movimento depende, igualmente, do ponto em que se encontra desenvolvida a subjetividade do indivíduo ou grupo social.
} 
assimilação dos elementos do mundo que despertem somente o seu espírito objetivo ${ }^{4}$ (SIMMEL, 1971).

Quando Simmel expõe suas teses seguindo esta orientação, tem em mente algumas das singularidades do mundo moderno e, dentre elas, a divisão social do trabalho que, grosso modo, distancia o homem de sua capacidade de atribuição de sentido ao objeto produzido com o seu trabalho (SOUZA; ÖELZE, 2005). A relação do indivíduo com o produto de seu trabalho se restringe ao plano teleológico, ao reconhecimento de que a produção existe por si mesma, enquanto produção. Não haveria, portanto, outro propósito senão algo puramente objetivo, minando a potencialidade significativa do espírito subjetivo (SIMMEL, 2000).

Neste caso, entender a produção como algo em si mesmo é visualizá-la como superior ao indivíduo, de maneira a colocá-la em um segundo plano, quase irrelevante. Logo, através deste ponto, nota-se como a compreensão do indivíduo dentro do processo produtivo tende a se restringir ao plano puramente objetivo, o que o obriga não somente a posicionar o produto na esfera objetiva, mas, igualmente, a si mesmo e à produção no mesmo lugar. Neste caso, restringe-se, igualmente, a relação com o material produzido a algo puramente formal, obrigatório, que ativa exclusivamente o seu veio objetivo de consideração ao produto. 0 resultado é o distanciamento do indivíduo para com 0 produto final.

Entretanto, não se deve considerar que o espírito subjetivo não tenha atuado na consideração semântica da importância do produto, no que se refere à constituição da vida e da realidade e, portanto, da sociabilidade do indivíduo que o produziu. Pelo contrário, a esfera subjetiva participa desta consideração e classificação do produto. Entretanto, a sua subjetividade, ao captar a essência de sua alma — na delimitação do plano de atuação do indivíduo na produção de uma matéria através do espírito subjetivo (entendido enquanto manifestação consciente da alma) - configura-se como algo absolutamente fragmentado, sendo impossível delimitar um campo significativo

\footnotetext{
${ }^{4}$ Interessante pensar que, ao se comprometer a radicalização deste pensamento em uma estratégia de manipulação do elemento racional - uma vez que os indivíduos providos de um determinado tipo de poder sobre os bens materiais são capazes de dominar estruturas específicas da constituição do social chegar-se-á a uma fórmula de dominação desenvolvida posteriormente pela Escola de Frankfurt, principalmente através de Adorno e Horkheimer (ADORNO; HORKHEIMER, 2006). A lógica é convidativa, mas deve-se ter cuidado em sua expressividade. Porém, não há como negar a simpatia dos teóricos frankfurtianos ao pensamento de Simmel (WAIZBORT, 2006).

${ }^{5}$ Por isso a dialética do abstrato se torna um ótimo indicador para a compreensão do pensamento simmeliano. Através da consideração dialética se pode pressupor o entendimento do ser humano como em constante contato com o seu meio. 0 importante, em Simmel, seria o tipo de ser humano e o tipo de meio que estariam em contato. A objetivação excessiva da modernidade transpõe ambos, meio (ou realidade) e indivíduo, para um patamar diferenciado em que desponta a objetividade nos dois lados, promovendo um redimensionamento do caráter subjetivo semântico (WAIZBORT, 2006).
} 
suficientemente sólido para determinado objeto produzido. Novamente, isso se dá de maneira clara pela divisão social do trabalho e pela participação subjetiva fragmentada dos inúmeros trabalhadores da modernidade (SIMMEL, 2000).

Portanto, no entendimento de Simmel, a divisão social do trabalho, essa irrevogável característica da forma de produção da modernidade, compele o sujeito a um patamar puramente produtivo, em que a sua subjetividade tende a ocupar um espaço secundário. 0 limite para a ação subjetiva se restringe não mais a atribuir significado ao material que está sendo produzido em um todo no qual a sua individualidade encontra-se inserida. Agora, a ação subjetiva encontra-se no plano da produção que, enquanto lógica, supera a existência de um objeto. 0 que importa agora é a matéria, embora a subjetividade continue tendo uma participação na composição final do objeto. Todavia, a determinação de seu significado não mais pode ser atribuída de maneira pura pelo indivíduo, uma vez que a linha produtiva o determina previamente. Assim sendo, a subjetividade passa a se encontrar limitada àquilo que a esfera produtiva determina como necessário (SOUZA; ÖELZE, 2005).

A constituição da sociedade urbana moderna enceta a preocupação sociológica quanto à constituição fragmentária da subjetividade, a ponto de fragilizá-la nas possibilidades de manifestações diante do mundo. Isso ocorre porque, grosseiramente falando, a fração subjetiva de um indivíduo que participa da constituição de um determinado objeto não necessariamente atuará a ponto de constituir de maneira definitiva 0 todo do objeto. A sua capacidade de interpretação da realidade, processo subjetivo que se dá de forma a apreender abstratamente os objetos que constituem esta mesma realidade, encontra-se igualmente fragilizada, em função da ausência de uma referência de sentido. Logo, o processo metafísico de desenvolvimento cultural encontrará barreiras para se consolidar e a apreensão das objetividades tenderá a promover uma manifestação praticamente objetiva no indivíduo. 0 impacto para a configuração de sua razão e de suas ações racionais é notável.

Eis a importância de se considerar a dialética do concreto anteriormente no pensamento simmeliano (WAIZBORT, 2006). É possível perceber através dela o quão comprometido se encontra o desenvolvimento subjetivo do indivíduo e, logicamente, a sua capacidade de ressignificação do mundo. 0 mundo, mais do que nunca inapreensível, torna-se algo fragmentado, desprovido de uma unicidade e potencialidade significativa a ponto de configurar uma importância definitiva, em termos semânticos, para os indivíduos que nele se encontram. A sociabilidade, irrevogável pela sua imanência, não pára nem mesmo para esperar a reconstituição subjetiva do indivíduo. Aliás, ela está e sempre esteve completamente atrelada a cada um deles e com o mundo a que pertencem. Assim, a sua definição, igualmente, encontra-se comprometida. 0 que resta em meio a tantos fragmentos? Ora, a manifestação praticamente pura dos elementos objetivos. 
[...] como nossa vida exterior é envolta por um número crescente de objetos, cujo espírito objetivo empregado em seus processos de produção não examinamos a fundo, de uma maneira distanciada, também a nossa vida íntima e social é preenchida por construções tornadas simbólicas, nas quais uma espiritualidade abrangente é armazenada - o espírito individual, no entanto, aproveita-se apenas minimamente delas. Esta discrepância entre a cultura tornada objetiva e a subjetiva parece expandir-se permanentemente. 0 acervo da cultura objetiva é aumentado diariamente e de todos os lados, enquanto o espírito individual somente pode estender as formas e conteúdos de sua constituição em uma aceleração contida, seguindo apenas de longe a cultura objetiva (SIMMEL, 2005 apud SOUZA; ÖELZE, 2005, p. 45).

Grosso modo, em termos históricos, a cultura objetivada é aquela compartilhada, que se torna realidade em função da ação da esfera objetiva da espiritualidade dos indivíduos que compõem uma sociedade. Por isso, ela apresenta um aspecto fortemente histórico, ou seja, ligado à história de determinada sociedade. A cultura subjetiva, por sua vez, está diretamente ligada a uma dimensão propriamente subjetiva do indivíduo social que, não necessariamente, possui um peso histórico determinante. Não há um determinismo histórico dentro de uma cultura subjetiva e, por isso, Simmel a relaciona a sociedades mais primitivas. Para culturas deste tipo, os objetos não adquirem o mesmo nível complexo de importância, como acontece em uma cultura objetiva. A consciência que um indivíduo de uma sociedade primitiva tem de si mesmo é absolutamente diversa daquela do indivíduo na sociedade moderna (SIMMEL, 2000).

Neste ínterim, em se tratando de considerações quanto ao mundo, há que se notar a prerrogativa da sociabilidade enquanto processo de compreensão e assimilação do mundo. Aqui está a coincidência entre Weber e Simmel no que tange ao posicionamento do indivíduo dentro deste mundo. Toma-se como orientação o fato de os dois sociólogos considerarem o indivíduo como parte fundamental para as ações. Contudo, Simmel transcende filosoficamente Weber ao propor um posicionamento metafísico do indivíduo na relevância do abstrato em constante comparação com 0 concreto. A história ${ }^{6}$, em termos de ocidente moderno, por si só, é revelada como algo capaz de desvendar o desenvolvimento inevitável que, tanto em Weber como em Simmel, é ambíguo. No primeiro por eclodir no cúmulo da racionalização e posicionar 0 indivíduo como protagonista do mundo. Todas as ações humanas, boas ou ruins, podem

\footnotetext{
${ }^{6}$ Ao se falar em história, em Simmel, é importante partir do pressuposto por ele desenvolvido de que o conhecimento objetivo constitui uma cópia da cultura objetiva. Assim, compreende-se o papel ocupado pela história em sua teorização ao se tomar como referência o fato de que a cultura objetiva desenvolveuse historicamente, interferindo diretamente no formato adquirido pelo conhecimento humano (SIMMEL, 2011).
} 
ser justificadas racionalmente. Simmel, por sua vez, apresenta a crescente manifestação do espírito objetivo como algo configurador da sociedade moderna que, por mais que obrigue 0 ser humano a se voltar para o seu interior (e supostamente passar por processos de ressignificação das coisas em si), também implica coerção objetiva da subjetividade (WOLF, 1950).

A racionalidade, em Simmel, também existe em sua concepção de indivíduo estando muito mais diretamente relacionada à constituição de sua essência. 0 indivíduo moderno, portanto, é racional e as relações sociais se estabelecem tendo como parâmetro tal racionalidade. Esta, portanto, orienta as suas ações, mas não nega a subjetividade do indivíduo. A existência de tal subjetividade torna-se premente na observação da heterogeneidade da sociabilidade. Cada indivíduo possui uma essência racional, mas a subjetividade denota a sua diferença do outro. 0 grande questionamento, para Simmel, refere-se ao fato de o comportamento racional orientar a manipulação das subjetividades nas relações sociais. Isto é, tais subjetividades perderiam autonomia em suas expressividades, pois o racionalismo operaria a ordem do comportamento social (SIMMEL, 1971).

0 problema todo, em se tratando de razão, está em reconhecer o lugar ocupado pela racionalidade ao posicioná-la não mais na constituição do indivíduo, mas sim na constituição do mundo. Ora, trata-se, como visto anteriormente, de um mundo moderno cada vez mais objetivado em função da divisão social do trabalho, dentre outros elementos. Do antigo, pode-se definir a relação social como continuidade de manifestação das individualidades sempre em constante contato entre si e com 0 mundo. Estando este mundo objetivado, desprovido de uma significativa manifestação subjetiva e, portanto, distante dos indivíduos em suas singularidades, o que restaria para o contato e relacionamento com os indivíduos são subjetividades fragmentadas e, também, elementos objetivos. Tendo em vista o comportamento racional, orientado como algo imanente à constituição do homem moderno, todos os indivíduos seriam manipulados por tal racionalidade que sobrepõe a subjetividade à objetividade. Em consequiência, tal racionalidade se da de forma puramente objetiva.

\section{CONSIDERAÇÕES FINAIS}

Simmel escreve no princípio do século XX, exatamente no momento em que a modernidade se colocaria a si mesma à prova (HABERMAS, 2000). 0 período é marcante por aguçar a curiosidade devido às novas formas sociais vislumbradas a partir da urbanização e a consequente reorganização da forma produtiva, sumamente capitalista. 0 ponto essencial da consideração do pensamento simmeliano, que se torna extremamente colaborativo para a compreensão do processo de formação da modernidade, encontra-se na capacidade de conceber o indivíduo não somente como 
um ente capaz de manipular objetos conforme uma orientação racional previamente determinada. Trata-se, pelo contrário, de perceber o alcance da racionalidade e o seu processo de formação a partir do entendimento do papel ocupado pela subjetividade. A sociedade moderna se constrói num movimento constante e ininterrupto de dialética entre esta subjetividade e o concreto.

Ao almejar uma compreensão mais abrangente, capaz de abarcar uma perspectiva até mesmo cultural, Simmel permite que o seu olhar para as relações sociais e para os processos de socialização seja feito por meio de uma construção dialética que leve em conta 0 abstrato, proveniente do universo subjetivo, e o concreto, decorrente da objetividade. 0 mundo, portanto, não seria somente um ou outro. É exatamente a conjunção das duas esferas (subjetividade e objetividade) que permite o entendimento acerca do social, assimilando a capacidade de o ser humano atribuir sentido às coisas e de as coisas fazerem sentido para ele. É precisamente por isso que o mundo moderno se torna atípico e rompe com um fluxo sócio histórico, ao induzir o indivíduo a uma compreensão restritamente objetivada do mundo. Diante da sociologia de Simmel, a construção de um ambiente cultural, no qual o sentido das coisas interfere na sociabilidade, encontra-se comprometida pela predominância dos objetos imputada pela modernidade produtiva capitalista, tal como pela fragmentação subjetiva daí decorrida.

A reflexão promovida a partir da obra de Simmel tem como norte fundamental tentar não somente interpretar seu pensamento, tido como clássico. Trata-se, muito mais, de ampliar bases para uma interpretação sociológica do mundo contemporâneo, ainda que ele também esteja, de alguma forma, inserido nesta mesma esfera produtiva capitalista. Até que ponto a construção de culturas, através de atribuições de sentidos a objetos presentes no mundo, é possível na atualidade? Aliás, até que ponto as próprias relações sociais se encontram comprometidas pela fragmentação subjetiva, condicionando os indivíduos a um cálculo puramente objetivo do mundo? A resposta talvez seja mais longa, mas a dúvida é premente.

\section{REFERÊNCIAS}

ADORNO, Theodor; HORKHEIMER, Max. A dialética do esclarecimento: fragmentos filosóficos. Rio de Janeiro: Jorge Zahar, 2006.

HABERMAS, Jürgen. O discurso filosófico da modernidade. São Paulo: Martins fontes, 2000 .

SIMMEL, Georg. On individuality and social forms: selected writings. Chicago: University of Chicago Press, 1971. 
SIMMEL, Georg. Simmel on culture: selected writings. Londres: Sage, 2000.

SIMMEL, Georg. Questões fundamentais da sociologia: o indivíduo e a sociedade. Rio de Janeiro: Jorge Zahar, 2006a.

SIMMEL, Georg. The philosophy of money. Londres: Routledge, 2006b.

SIMMEL, Georg. Ensaios sobre teoria da história. Rio de Janeiro: Contraponto, 2011.

SOUZA, Jessé; ÖELZE, Berthold. Simmel e a modernidade. Brasília: Ed. Universidade de Brasília, 2005.

VANDENBERGHE, Frederic. As sociologias de Georg Simmel. Florianópolis: Ed. UFSC, 2006.

WAIZBORT, Leopoldo. As aventuras de Georg Simmel. São Paulo: Ed. 34, 2006.

WEBER, Max. A ética protestante e o espirito do capitalismo. São Paulo: Companhia das letras, 2005.

WOLF, Kurt (Org.). The sociology of Georg Simmel. Nova York: Free Press Paperback, 1950 . 